Computatio: Journal of Computer Science and Information Systems, 3/1 (2019), 77-84

\title{
PENGEMBANGAN APLIKASI E-COMMERCE PRODUK LOKAL DAN DATA KEPENDUDUKAN PADA DESA GIRITENGAH, BOROBUDUR
}

\author{
Benny Bunardi ${ }^{1}$, Dali S. Naga ${ }^{2}$, Desi Arisandi ${ }^{3}$ \\ ${ }^{1,2,3}$ Program Studi Sistem Informasi, Fakultas Teknologi Informasi, Universitas Tarumanagara, \\ Jln. Letjen S. Parman No. 1, Jakarta, 11440, Indonesia

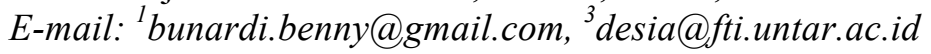

\begin{abstract}
Abstrak
Pariwisata merupakan salah satu sektor pendapatan yang cukup penting bagi suatu daerah. Warga yang tinggal di sekitar sebuah objek wisata mampu menonjolkan kebudayaannya melalui kerajinan tangan ataupun produk lokal yang ada. Sebuah sistem informasi pariwisata berbasis web telah dibuat. Namun keinginan masyarakat setempat untuk menjual produkproduk lokal yang ada secara luas dengan memanfaatkan jaringan internet belum dapat terwujud karena sistem tersebut belum memiliki sistem e-commerce. Selain kurangnya kemampuan sistem yang ada dalam menjual produk-produk lokal desa Giritengah, diharapkan pula adanya sebuah sistem yang dapat melakukan proses penyimpanan data demografi dan menampilkannya dalam bentuk informasi. Pengembangan aplikasi ini diharapkan dapat membantu warga untuk menjual produknya dan perangkat desa dalam mengelola data kependudukan. Metodologi pembuatan sistem menggunakan metode System Development Life Cycle (SDLC) dengan menggunakan bantuan software seperti HTML, PHP, MySQL dan Notepad ++ . Proses pembuatan program dimulai dengan mengimplementasikan rancangan Data Flow Diagram (DFD), Entity Relationship Diagram (ERD), serta hubungan antar tabel ke dalam program hingga melakukan pengujian oleh programmer melalui metode blackbox testing dan user dengan metode User Acceptance Testing. Penulisan ini menghasilkan sebuah sistem yang dapat membantu warga Giritengah dalam menjual produk lokalnya serta membantu perangkat desa Giritengah dalam melakukan pengelolaan data penduduknya.
\end{abstract}

Kata kunci - Giritengah, E-commerce, Kependudukan, Pengembangan Sistem, Web

\begin{abstract}
Tourism is one of the most important sector of revenue for an area. The people living near the tourist attraction can introduce their culture by showing some local products or their handcraft. Previously a tourism information system has been made. But the system cannot facilitate the desire of the local to sell their product by using internet. Besides the lack of capability of the system to sell product, the locals also expect a system to be capable of recording some of the civilian data and turn it into information. The development of the previous version is expected to help some locals to sell their products and to help the village to manage their data about the resident in that village. This system uses System Development Life Cycle (SDLC) with some help of software such as HTML, PHP, MySQL, and notepad++. The making process of the program starts with designing Data Flow Diagram (DFD), Entity Relationship Diagram (ERD), and table relation, then being tested by the programmer using blackbox testing method and User Acceptance Testing. This writing results in a system to help Giritengah to sell local product and the village to manage their residence data.
\end{abstract}

Keywords - Giritengah, E-commerce, Population, System Development, Web 


\section{PENDAHULUAN}

Sebuah sistem informasi pariwisata berbasis web telah dibuat untuk memberikan akses para calon wisatawan agar mereka lebih tahu tentang potensi pariwisata dan keindahan alam yang ada pada desa Giritengah. Sistem ini menampilkan beberapa informasi yang dapat digunakan oleh para calon wisatawan seperti profil desa, objek-objek wisata serta peta desa Giritengah [1].

Namun keinginan masyarakat setempat untuk menjual produk-produk lokal yang ada secara luas dengan memanfaatkan jaringan internet belum dapat terwujud karena sistem yang ada belum memiliki sistem e-commerce. Oleh karena itu, dilakukan pengembangan dari sistem sebelumnya dengan menambahkan fungsi e-commerce guna memfasilitasi keinginan warga desa Giritengah untuk menjual produknya.

Selain kurangnya kemampuan sistem yang ada dalam menjual produk-produk lokal desa Giritengah, diharapkan pula adanya sebuah sistem yang dapat melakukan proses penyimpanan data demografi dan menampilkannya dalam bentuk informasi. Sebuah sistem diharapkan karena apabila pencatatan dilakukan secara manual ada beberapa hal yang menjadi pertimbangan antara lain adalah kesalahan dalam pencatatan seperti pencatatan ganda, lambatnya pencarian data dan proses pembuatan laporan apabila dokumen yang ada sudah menumpuk. Kegiatan pencatatan yang umum terjadi pada data demografi adalah kelahiran, kematian, atau perpindahan penduduk Proses input data dilakukan oleh perangkat desa yang berwenang dan diolah oleh sistem untuk menjadi sebuah informasi.

Berdasarkan permasalahan yang sudah dibahas diatas, maka dilakukanlah pengembangan aplikasi sistem sebelumnya pada desa Giritengah, Borobudur dengan menambahkan 2 fungsi yaitu fungsi e-commerce dan pengelolaan data kependudukan.

Menurut Marakas dan O'Brien (2013:12) E-commerce adalah kegiatan pembelian, penjualan, pemasaran dan pelayanan atas produk, jasa, dan informasi melalui berbagai macam jaringan komputer. Bisnis-bisnis pada saat ini menggunakan internet, intranet, extranet, dan jaringan lainnya untuk mendukung setiap langkah pada proses komersial, termasuk segala hal dalam pengiklanan, penjualan dan dukungan konsumen pada web hingga mekanisme keamanan pembayaran guna memastikan proses pengiriman dan pembayaran terselesaikan [2].

Manzoor (2010) menjelaskan bahwa e-commerce merujuk pada penggunaan elektronik dan teknologi untuk melakukan transaksi komersial, meliputi kegiatan bisnis dengan bisnis, maupun bisnis dengan konsumen. Pengiriman produk atau jasa dapat terjadi di dalam atau di luar layanan [3].

\section{METODE PENELITIAN}

Dalam pembuatan sebuah sistem, ada tahapan siklus hidup yang harus dilalui oleh sebuah sistem. Tahapan siklus hidup ini umumnya disebut dengan System Development Life Cycle $(S D L C)$. Siklus tersebut dimulai dari tahap awal yaitu perencanaan hingga implementasi. Perencanaan dimulai dengan merumuskan apa saja kemampuan sistem, siapa yang menggunakan sistem, batasan dan cakupan dari sistem. Tahapan selanjutnya dilakukan analisis sistem yang dimulai dengan mengidentifikasi permasalahan yang ada, memahami proses yang berjalan, mengumpulkan seluruh kebutuhan-kebutuhan sistem. Selanjutnya tahapan yang dikerjakan adalah desain yang dimulai dengan menggambarkan aliran proses dan data dari sistem yang dibuat, struktur penyimpanan data hingga rancangan antarmuka. Tahap terakhir dari 
SDLC adalah implementasi yang meliputi seluruh kegiatan penerapan sistem yang telah dibuat, pengujian sistem, hingga perawatan.

Dennis (2012:11) dalam bukunya mengemukakan bahwa sebuah sistem informasi harus melalui System Development Life Cycle (SDLC) yang memiliki 4 fase diantaranya: planning, analysis, design, dan implementation [4].

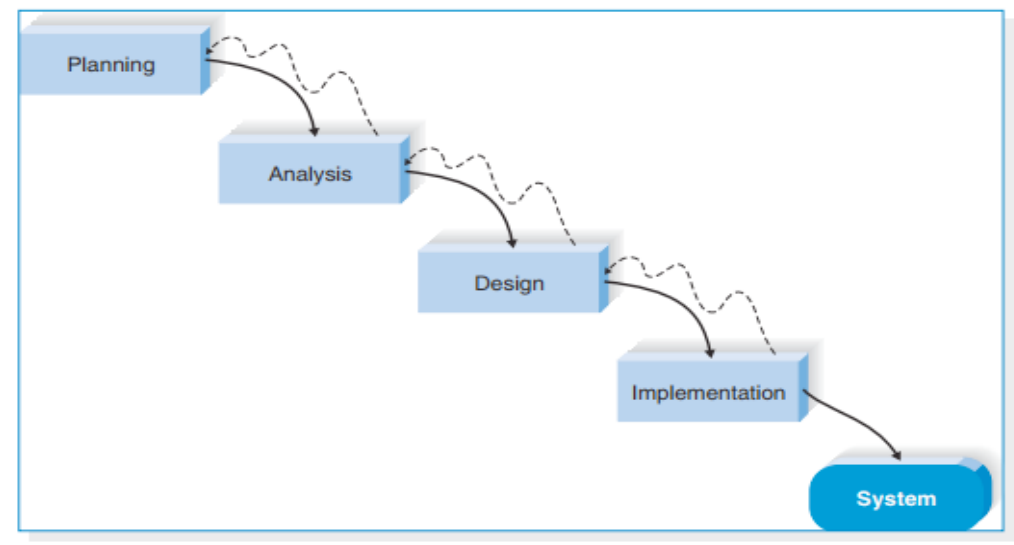

Gambar 1 Model System Development Life Cycle

Metode yang digunakan dalam pemodelan SDLC ini adalah waterfall. Metode pengembangan waterfall memiliki kelebihan karena identifikasi kebutuhan dilakukan jauh sebelum pemrograman dimulai dan adanya kemampuan untuk membatasi perubahan kebutuhan seiring dengan berjalannya proyek [4].

Dalam melanjutkan proses pembuatan sistem dengan menggunakan metode SDLC digunakan beberapa diagram pemodelan sistem untuk membantu pembuatan sistem seperti Data Flow Diagram (DFD) dan Entity Relationship Diagram (ERD).

Data Flow Diagram adalah sebuah tool yang digunakan untuk membuat diagram dengan menggunakan beberapa simbol sederhana untuk mengilustrasikan aliran data antara entitas external, aktivitas proses, dan elemen penyimpanan data [2].

Sedangkan Entity Relationship Diagram adalah model yang digunakan dalam menggambarkan basis data yang akan digunakan oleh sistem. Menurut Connoly, T. (2014) Basis data adalah adalah sebuah kumpulan dari data yang saling berkaitan. Sebuah basis data dikelola dan diatur oleh sebuah perangkat lunak yang bernama database management system (DBMS) [5]. Sedangkan menurut Stair (2012:15), basis data adalah kumpulan fakta dan informasi yang tersusun, yang biasanya terdiri atas dua data atau lebih yang berkaitan. Basis data pada sebuah organisasi dapat memuat fakta dan informasi mengenai karyawan, pelanggan, persediaan barang, penjualan kompetitor, pembelian, dan lainnya [6].

Menurut Silberschatz (2011:17) Entity Relationship Diagram atau ERD adalah sebuah diagram yang digunakan untuk menggambarkan sebuah pemodelan penyimpanan data yang terdiri dari kumpulan objek-objek yang disebut dengan entities dan relationship di antara objekobjek tersebut. Sebuah entity adalah "benda" atau "objek" yang ada pada dunia nyata dan dapat dibedakan dengan objek lainnya. Sebagai contoh, tiap-tiap manusia adalah sebuah entity dan akun bank dapat dianggap sebagai entity [7]. 


\section{HASIL DAN PEMBAHASAN}

Proses pembuatan dan implementasi program aplikasi "Pengembangan Aplikasi Sistem Informasi Pariwisata Berbasis Web Desa Giritengah, Borobudur" dilakukan dengan menggunakan berbagai teknik dan perangkat lunak yang berfungsi untuk mendukung pembuatan dan penerapan program.

Selain teknik dan perangkat lunak yang digunakan, proses pembuatan dan penerapan juga membutuhkan perangkat keras yaitu sebuah komputer yang berjalan minimal pada sistem operasi Windows 7.

Setelah menyiapkan perangkat keras tersebut, rancangan program yang sebelumnya sudah dibuat seperti Data Flow Diagram atau Entity Relationship Diagram digunakan sebagai acuan dalam pembuatan. Kemudian pembuatan sistem dilakukan dengan menggunakan bahasa pemrograman PHP, CSS, HTML, dan Javascript untuk pembuatan website sedangkan untuk pembuatan basis data digunakan Bahasa pemrograman MySQL yang dibuat dalam perangkat lunak bernama Notepad++. Agar sistem dapat berjalan, sebuah perangkat lunak bernama XAMPP juga perlu di-install.

Langkah-langkah pembuatan program adalah: (1) menyiapkan perangkat keras beserta perangkat lunak yang seperti Notepad++ dan XAMPP; (2) mempersiapkan rancangan tabel yang telah dibuat pada diagram hubungan antar tabel; (3) membuat tabel dengan menggunakan database MySQL; (4) membuat fungsi input data untuk admin dengan menggunakan bahasa pemrograman HTML, PHP, dan Javascript; (5) membuat fungsi front-end system bagi user; (6) melakukan pengujian blackbox testing oleh programmer dan User Acceptance Testing (UAT); (7) melakukan perawatan sistem dengan cara mem-backup data dari MySQL secara berkala. Berikut ini adalah tampilan aplikasi yang telah dibuat.

\begin{tabular}{|c|c|}
\hline Laki-laki & v \\
\hline \multicolumn{2}{|l|}{ Kewarganegaraan } \\
\hline Warga Negara Indonesia & v \\
\hline \multicolumn{2}{|l|}{ Golongan Darah } \\
\hline - & r \\
\hline \multicolumn{2}{|l|}{ Pekerjaan } \\
\hline Karyawan & v \\
\hline \multicolumn{2}{|l|}{ Pendidikan } \\
\hline SD / Sekolah Dasar & $\checkmark$ \\
\hline \multicolumn{2}{|l|}{ Agama } \\
\hline Islam & ' \\
\hline \multicolumn{2}{|l|}{ Kartu Keluarga } \\
\hline 3173031106961102 & v \\
\hline \multicolumn{2}{|l|}{ Status Keluarga } \\
\hline Kepala Keluarga & $\checkmark$ \\
\hline Back to view & Submit \\
\hline
\end{tabular}

Gambar 2 Halaman Input Penduduk 


\begin{tabular}{|c|c|}
\hline \multicolumn{2}{|l|}{ Input Data Produk } \\
\hline \multicolumn{2}{|l|}{ Nama Produk } \\
\hline \multicolumn{2}{|l|}{ Masukkan nama produk } \\
\hline \multicolumn{2}{|l|}{ Stok Produk } \\
\hline \multicolumn{2}{|c|}{ Masukkan jumlah stok produk } \\
\hline \multicolumn{2}{|l|}{ Deskripsi Produk } \\
\hline \multicolumn{2}{|c|}{ Masukkan deskripsi produk } \\
\hline \multicolumn{2}{|l|}{ Berat Produk (gram) } \\
\hline \multicolumn{2}{|l|}{ Masukkan berat produk } \\
\hline \multicolumn{2}{|l|}{ Harga Produk } \\
\hline \multicolumn{2}{|l|}{ Masukkan harga produk } \\
\hline \multicolumn{2}{|l|}{ Nama Penjual } \\
\hline benny bunardi & $\checkmark$ \\
\hline \multicolumn{2}{|l|}{ Kategori Produk } \\
\hline Kecantikan & v \\
\hline \multicolumn{2}{|l|}{ Asal Objek Wisata } \\
\hline Punthuk Sukmojoyo & $\checkmark$ \\
\hline \multicolumn{2}{|l|}{ Upload Gambar Produk } \\
\hline Choose Files No filec & \\
\hline Back to view & Submit \\
\hline
\end{tabular}

Gambar 3 Halaman Input Produk

PESONA GIRITENGAH

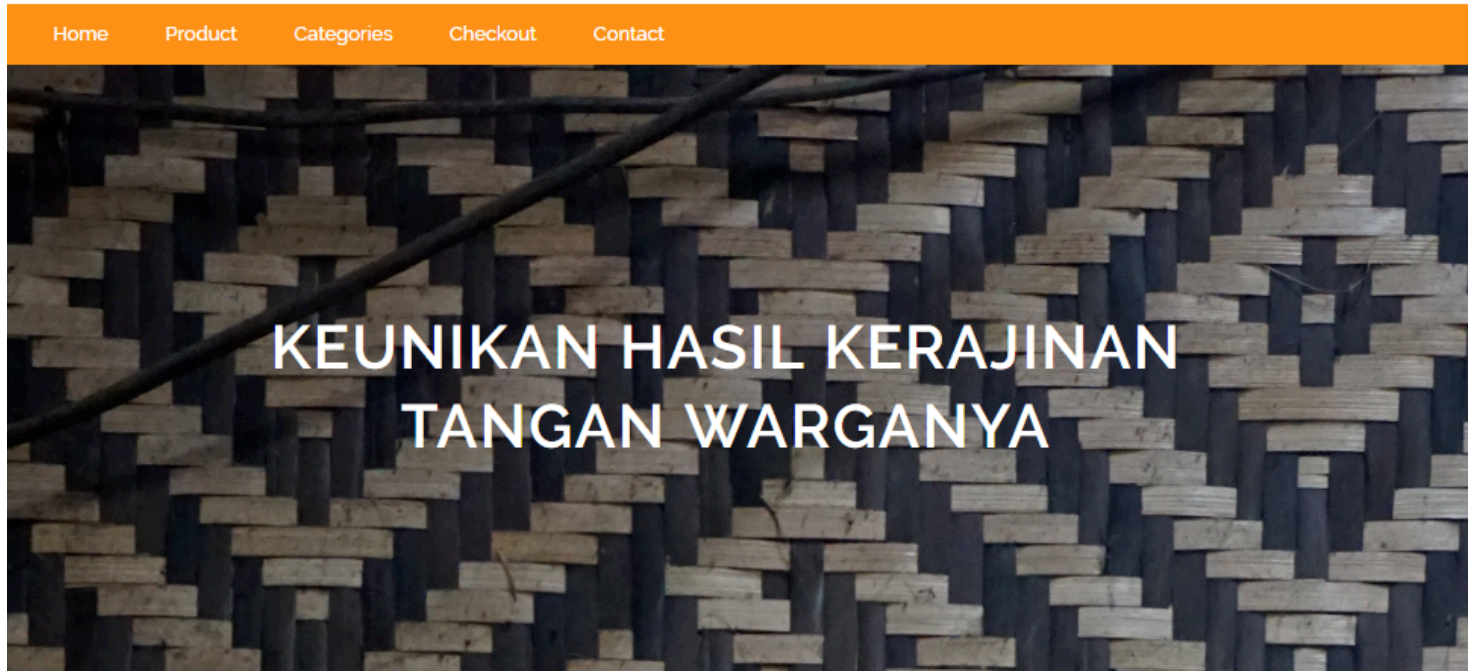

Gambar 4 Tampilan Home E-commerce 


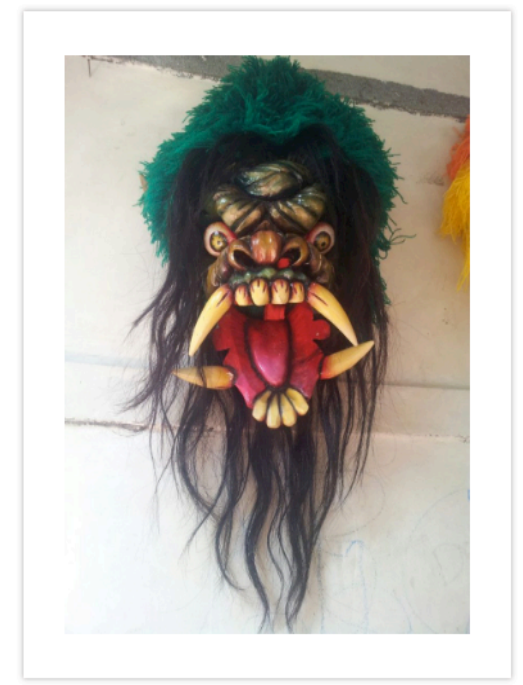

\section{TOPENG BUTO}

Seller :

Josua Marojahan Manurung

Objek Wisata :

Ukiran Topeng Kayu

DESCRIPTION

Bahan dasar topeng adalah kayu puie (jenis kayu yang tidak keras). Aneka bentuk

topeng vang dibuatnva selain dikoleksi ruga sebagai perlengkapan keseruan

tradisional. Proses pembuatan: Kayu ditatah, diamplas, dimeni, lalu dicat Pembeli

topeng buatan Irwandi di-antaranya turis asing dari Australia, dan Malaysia yang

menyukai miniatur topeng untuk gantungan kunci Sedangkan topeng buto

ukuran besar peminatnya wisatawan lokal, dan untuk perlengkapan tari

tradisional.

Rp 200.000

ADD TO CART

Gambar 5 Tampilan Detil Produk

PESONA

Search for a Product...

\section{GIRITENGAH}

\section{Home Product Categories Checkout Contact}

A Home / Checkout Page

TERIMA KASIH ATAS PESANAN ANDA

Total Pembayaran Anda adalah : Rp1.550.000

Mohon untuk melakukan pembayaran melalui transfer bank ke rekenening yang tertera di layar ini

\section{Bank Mandiri}

\section{1}

A.n. Koperasi Giritengah

setelah melakukan pembayaran, customer diharapkan untuk melakukan konfirmasi pembayaran dengan mengisi data pembayaran.

Pesanan anda akan segera kami proses setelah pembayaran terkonfirmasi.

Terima Kasih

Gambar 6 Tampilan Informasi Pembayaran 


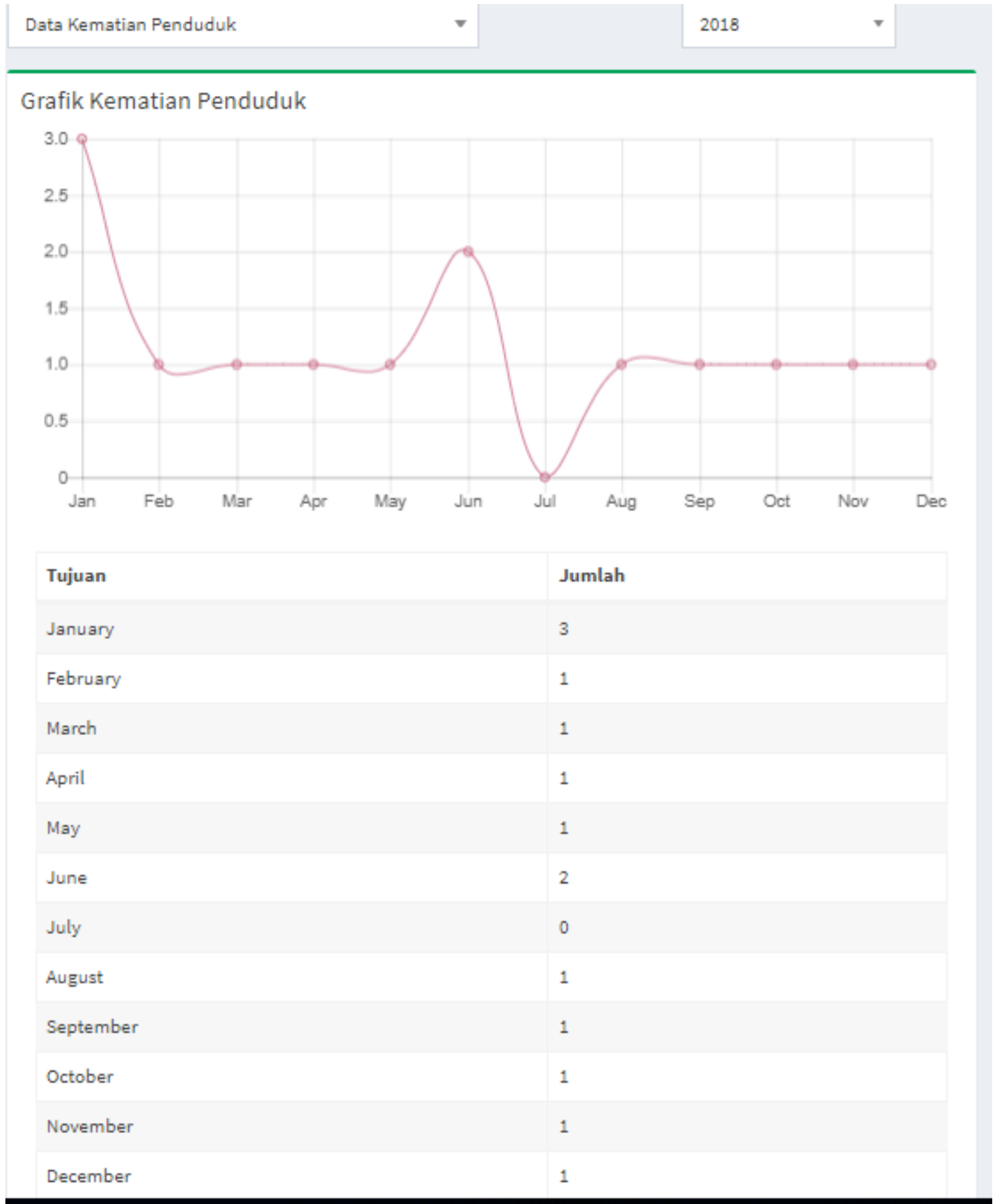

Gambar 7 Tampilan Grafik Kematian Penduduk

\section{KESIMPULAN}

Kesimpulan yang diporelah dari hasil pembuatan pengembangan aplikasi sistem informasi pariwisata berbasis web desa Giritengah, Borobudur adalah (1) sistem yang dibuat dapat membantu warga Giritengah untuk menjual produk lokal mereka sistem E-commerce; (2) sistem pengelolaan data kependudukan dapat membantu perangkat desa dalam mencatat, 
mengelola, dan memperoleh data kependudukan seperti jenis kelamin, agama, pekerjaan, dan sebagainya; dan (3) website E-commerce selain membantu warga menjual produk lokal, juga membantu promosi pariwisata di desa Giritengah. Untuk pengembangan sistem ke depannya diharapkan dilakukan peningkatan seperti (1) menambahkan front-end agar data kependudukan dapat dilihat warga guna transparansi data.; (2) menggunakan framework dalam pembuatan program untuk meningkatkan keamanan sistem; dan (3) menambahkan fitur untuk melakukan share produk yang ada pada e-commerce ke media sosial.

\section{DAFTAR PUSTAKA}

[1] Sherly. (2017). Perancangan Aplikasi Sistem Informasi Pariwisata Berbasis Web untuk Desa Giritengah, Borobudur. Skripsi tidak dipublikasikan. Jakarta: Universitas Tarumanagara.

[2] Marakas, G. M. \& O'Brien, J. A. (2013) Introduction to Information Systems, $16^{\text {th }}$ Ed. The McGraw-Hill Companies, Inc.

[3] Manzoor, A. (2010). E-Commerce : An Introduction. Lap Lambert Academic Publishing.

[4] Dennis, A., Roth, R. M., \& Wixom, B. H. (2012). Systems Analysis \& Design, $5^{\text {th }}$ Ed. John Wiley \& Sons, Inc.

[5] Connoly, T. M., \& Begg, C. E. (2015). Database Systems: A Practical Approach to Design, Implementation, and Management, $6^{\text {th }}$ Ed. Pearson Education Limited.

[6] Stair, R. \& Reynolds, G. (2012). Principles of Information Systems, 10 ${ }^{\text {th }}$ Ed. Course Technology, Cangage Learning.

[7] Silberschatz, A., Korth, H. F., \& Sudarshan, S. (2011). Database System Concepts, $6^{\text {th }}$ Ed. The McGraw-Hill Companies, Inc. 